\title{
Effects of scopolamine and physostigmine on tonic immobility in ducks and guinea pigs
}

\author{
MICHAEL L. WOODRUFF \\ Middlebury College, Middlebury, Vermont 05753
}

and

\author{
DANIEL C. HATTON, MATT B. FRANKL, and MERLE E. MEYER \\ University of Florida, Gainesville, Florida $\$ 2611$
}

\begin{abstract}
The present study was performed to test the effects of the anticholinergic drug scopolamine and the cholinergic-potentiating drug physostigmine on tonic immobility (TI) in ducks and guinea pigs. Scopolamine shortened the duration of the response in ducks, while increasing TI duration in guinea pigs. Physostigmine, on the other hand, increased TI duration in ducks, while shortening the response in guinea pigs. Though the neurochemical systems mediating the response may differ, it is suggested that TI could serve as a useful model behavior for studying functional homology between the brains of birds and mammals.
\end{abstract}

Tonic immobility (TI), or "animal hypnosis," can be produced in members of a wide variety of species by sudden inversion and restraint. TI is characterized by a reduction in reactivity to external stimuli, loss of the righting reflex, and depression of flexor and extensor polysynaptic reflexes. It has been suggested that fear-producing stimuli play a role in the initial induction and subsequent maintenance of this response (Gallup, 1974; Ratner \& Thompson, 1960). This proposition is supported by the observation that presentation of noxious stimuli prior to or during TI will increase susceptibility to and duration of TI in chicks (Gallup, Creekmore, \& Hill, 1970) and in guinea pigs (Leftwich \& May, 1974).

Several studies suggest that anticholinergic drugs affect a neural system mediating fear. For example, deficits in passive avoidance behavior have been observed after injection of scopolamine (Calhoun \& Smith, 1968), and anticholinergic drugs have been reported to decrease the conditioning of fear (Daly, 1968 ), as well as the occurrence of freezing responses (Stone, 1960). More recently, Plotnik, Mollenauer, and Snyder (1974) observed that rats given scopolamine showed significantly less freezing in the presence of a cat than did controls. Moreover, the scopolamine-treated rats approached the cat significantly more often and even ate in its presence. These results support the hypothesis that a central cholinergic fear system exists.

If the proposition is accepted that TI is, at least in part, a fear response, the results of a study of cholinergic modulation of TI in chicks by Thompson, Piroch, Fallen, and Hatton (1974) are congruent with

Requests for reprints should be sent to Michael L. Woodruff, Department of Psychology, Middlebury College, Middlebury, Vermont 05753 . a cholinergic fear hypothesis. These authors found that the anticholinergic scopolamine decreased TI, while physostigmine, a drug which increases cholinergic activity, increased the duration of TI.

When both the assumption that TI is fear related and the assumption that fear is correlated with increased activity in a central cholinergic system are accepted, the studies just cited form a consistent picture. However, the results of a recent study by Hatton, Woodruff, and Meyer (Note 1) do not fit with the above data. Hatton et al. found that scopolamine significantly increased the duration of TI in rabbits, while physostigmine virtually eliminated the response. These findings contradict those of Thompson et al. (1974) for chicks and also are inconsistent with the above assumptions concerning both TI and fear mediation. For this reason, guinea pigs and ducks were given scopolamine and physostigmine and tested for TI. This experiment attempts to replicate the findings of Thompson et al. and Hatton et al. in other avian and mammalian species.

\section{METHOD}

Subjects

Ninety White Pekin ducks (Anas platyrhynchose), 12 days old when they arrived in the colony, and 72 35-day-old guinea pigs (Cavia porcellus) served as subjects. The ducks were housed in a commercial brooder. The guinea pigs were housed in pairs in a separate room. A 12-12 light-dark cycle was in effect for both species, and food and water were available to all animals ad lib.

\section{Procedure}

The ducks were divided into nine groups with 10 ducks in each group. Three of the groups received one of three dose levels of scopolamine hydrobromide $(.5,1.5$, or $2.5 \mathrm{mg} / \mathrm{kg})$. Another group was given methyl scopolamine $(1.0 \mathrm{mg} / \mathrm{kg})$ as a control for the peripheral effects of scopolamine hydrobromide. Three groups of nine ducks received one of three 
Table 1

Median Scores for the Combination of the Duration of the Three Consecutive TI Trials Given Each Animal in Each Condition

\begin{tabular}{lrrlr}
\hline \multicolumn{1}{c}{ Guinea Pigs } & & & \multicolumn{2}{c}{ Ducks } \\
\cline { 1 - 3 } \cline { 5 - 6 } Condition & Mdn* & Condition & Mdn* \\
\hline No-Drug & 52 & & No-Drug & 115 \\
Methyl Scopolamine & 61 & & Methyl Scopolamine & 122 \\
Saline & 47 & & Saline & 131 \\
$.5 \mathrm{mg} / \mathrm{kg}$ Scopolamine & 55 & & $.5 \mathrm{mg} / \mathrm{kg}$ Scopolamine & 119 \\
$2.0 \mathrm{mg} / \mathrm{kg}$ Scopolamine & 132 & & $1.5 \mathrm{mg} / \mathrm{kg}$ Scopolamine & 57 \\
$4.0 \mathrm{mg} / \mathrm{kg}$ Scopolamine & 198 & & $2.5 \mathrm{mg} / \mathrm{kg}$ Scopolamine & 13 \\
$.25 \mathrm{mg} / \mathrm{kg}$ Physostigmine & 64 & & $.1 \mathrm{mg} / \mathrm{kg}$ Physostigmine & 139 \\
$.1 \mathrm{mg} / \mathrm{kg}$ Physostigmine & 25 & & $.15 \mathrm{mg} / \mathrm{kg}$ Physostigmine & 232 \\
$.2 \mathrm{mg} / \mathrm{kg}$ Physostigmine & 9 & & $.2 \mathrm{mg} / \mathrm{kg}$ Physostigmine & 301 \\
\hline
\end{tabular}

*All median scores are expressed in seconds.

concentrations of physostigmine $(.1, .15$, or $.20 \mathrm{mg} / \mathrm{kg})$. Saline $(.5 \mathrm{cc})$ was given to another group, and the final group received no injection. All drugs were dissolved in saline and given intraperitoneally. The guinea pigs were also divided into nine groups. Eight guinea pigs served as no-drug controls, eight were given $.5 \mathrm{cc}$ of saline, and eight received $1.0 \mathrm{mg} / \mathrm{kg}$ methyl scopolamine. Three groups of eight guinea pigs received scopolamine hydrobromide in concentrations of .5, 2.0, or $4.0 \mathrm{mg} / \mathrm{kg}$, and three additional groups were given injections of physostigmine $(.25, .1$, or $.2 \mathrm{mg} / \mathrm{kg})$.

Ten days after arrival in the colony, four ducks and three guinea pigs from each drug or control condition were tested for TI as described below. On the next day, three ducks and two guinea pigs from each group were tested, and the remainder of the animals were tested on the following day. On the day of testing for TI, each duck or guinea pig was taken from the brooder or cage, weighed, and either given an injection of one of the drugs and placed in a cardboard box or just placed in a cardboard box. Twenty minutes later, the box was carried to the experimental space. TI induction was attempted by holding the animal around the thorax with one hand, quickly inverting it, and pressing it down into a V-shaped plywood trough (48 $\mathrm{cm}$ long $\times 24 \mathrm{~cm}$ high). Pressure was maintained on the thorax for $15 \mathrm{sec}$. The hand was then withdrawn, and if the subject remained immobile a clock was started. The clock was stopped when righting occurred, and the duration of TI in seconds was recorded. If the procedure did not produce TI and the subject righted as the hand was withdrawn, induction was repeated $15 \mathrm{sec}$ later. Three trials were given in this manner for every TI test session.

\section{RESULTS}

The median scores presented in Table 1 are based on composite scores obtained by combining the durations of the three consecutive TI trials given each animal in each condition. Kruskal-Wallis one-way analyses of variance corrected for ties (Siegel, 1956) were conducted on the combined durations of TI from each species. A significant effect was found in the data from the ducks $(H=26.77, \mathrm{df}=8, \mathrm{p}<.001)$. Subsequent one-tailed Mann-Whitney, U tests revealed that for the ducks the nondrug, saline, methyl scopolamine, $.5 \mathrm{mg} / \mathrm{kg}$ scopolamine, and $.1 \mathrm{mg} / \mathrm{kg}$ physostigmine treatments did not result in significant differences in TI duration. The $1.5 \mathrm{mg} / \mathrm{kg}$ and $2.5 \mathrm{mg} / \mathrm{kg}$ levels of scopolamine produced significantly shorter durations as compared to the other groups ( $p<.01$ for all comparisons), while the TI duration in the group given $2.5 \mathrm{mg} / \mathrm{kg}$ scopolamine was significantly shorter than the duration of the group given $1.5 \mathrm{mg} / \mathrm{kg}(\mathrm{p}<.05)$. The ducks given the $.15-$ and $.20-\mathrm{mg} / \mathrm{kg}$ injections of physostigmine demonstrated significantly longer TI durations than any of the other groups ( $p<.01$ for all comparisons), but did not differ statistically from each other $(p<.05)$.

Analysis of the data from the guinea pigs indicated overall statistical significance $(\mathrm{H}=30.24, \mathrm{df}=8$, $\mathrm{p}<.001)$. Subsequent Mann-Whitney U tests indicated that the control groups (nondrug, saline, and methyl scopolamine) did not differ from each other statistically. The guinea pigs given $.5 \mathrm{mg} / \mathrm{kg}$ of scopolamine and those given $.25 \mathrm{mg} / \mathrm{kg}$ of physostigmine did not differ from the control groups or from each other. However, the group given $2.0 \mathrm{mg} / \mathrm{kg}$ of scopolamine exhibited significantly longer durations of TI ( $\mathrm{p}<.01$ for all comparisons) than any other group, except the group given $4.0 \mathrm{mg} / \mathrm{kg}$ scopolamine. The group given $4.0 \mathrm{mg} / \mathrm{kg}$ scopolamine had the longest durations observed in the guinea pigs $(p<.01$ for all comparisons except the $2.0-\mathrm{mg} / \mathrm{kg}$ condition, which yielded $\mathrm{p}<.05)$. The $.1-\mathrm{mg} / \mathrm{kg}$ injection of physostigmine produced significantly shorter durations of TI in guinea pigs than did all other treatments $(p<.01$ for all comparisons), with the exception of the $.2-\mathrm{mg} / \mathrm{kg}$ dose of physostigmine which produced even shorter durations ( $\mathrm{p}<.01$ for all comparisons).

Finally, the number of successful TI inductions under each condition were compared using a chi square for related samples. No differences were found in this measure as a consequence of drug administration in any group of animals.

\section{DISCUSSION}

The results of the present study support the biphasic action of the cholinergic system on TI in mammals and birds. As with chickens (Thompson et al., 1974), physostigmine increased duration of TI in ducks, while scopolamine decreased duration. But in guinea pigs, physostigmine shortened TI duration, while scopolamine prolonged it. These latter observations concur with those of Hatton et al. (Note 1) for rabbits.

As indicated above, it has been proposed (Gallup, 1974; Ratner \& Thompson, 1960) that manipulations which produce fear potentiate TI in many species. Furthermore, fear has been related to activity within the cholinergic system. The data from the guinea pigs in the present study, as well as from rabbits in the study by Hatton et al. are not congruent with these propositions. These data do not refute the fear 
hypothesis of TI induction or the idea that the central cholinergic system is involved in fear. However, if one accepts the hypothesis that increasing cholinergic activity results in increased fear as measured by several behavioral changes (Calhoun \& Smith, 1968; Daly, 1968; Plotnik et al., 1974; Stone, 1960), it is difficult to attribute the prolongation of TI duration induced in the rabbit and guinea pig by scopolamine to changes in fear. Moreover, if fear were in some way manipulated by the drugs, one might expect the number of successful TI inductions to change. That is, if the animals became more fearful, in addition to changes in TI duration, it would seem that TI should be induced more often. This was not the case in either the present study or in the study by Hatton et al.

In conclusion, it is suggested that there is a significant cholinergic influence on TI. Whether that influence is manifested through systems mediating fear, or in some other way is a matter for future research. Whatever the relationship between cholinergic drugs and TI, the divergent nature of the relationship across species may provide an excellent model for comparative research into cholinergic systems, in that, because of the similarity in topography and means of induction, TI could be a useful behavior in the study of functional homology between neurochemical systems in birds and mammals.

\section{REFERENCE NOTE}

1. Hatton, D. C., Woodruff, M. L., \& Meyer, M. E. Cholinergic modulation of tonic immobility in the rabbit (Oryctolagus cuniculus), in preparation.

\section{REFERENCES}

Calmoun, W. H., \& Smith, A. A. Effects of scopolamine on acquisition of passive avoidance. Psychopharmacologia. 1968, 13, 201-209.

DALY, H. B. Disruptive effects of scopolamine on fear conditioning and on instrumental escape learning. Journal of Comparative and Physiological Psychology, 1968, 66, 579-583.

GalluP, G. G., JR. Animal hypnosis: Factual status of a fictional concept. Psychological Bulletin, 1974, 11, 836-853.

Gallup, G. G., JR., Creekmore, H. S., \& Hill, W. E., III. Shock-enhanced immobility reactions in chickens: Support for the fear hypothesis. Psychological Records, 1970, 20, 243-245.

Leftwich, D., \& MAY, J. G. Effects of conditioned aversive stimuli presented during tonic immobility in guinea pigs. Journal of Comparative and Physiological Psychology, 1974, 87, 513-516.

Plotnik, R., Mollenauer, S., \& SNyder, E. Fear reduction in the rat following central cholinergic blockade. Journal of Comparative and Physiological Psychology, 1974, 86, 1074-1082.

RATner, S. C., \& Thompson, R. W. Immobility reactions (fear) of domestic fowl as a function of age and prior experience. Animal Behaviour, 1960, 8, 186-191.

SIEGEL, S. Nonparametric statistics for the behavioral sciences. New York: McGraw-Hill, 1956.

Stone, G. C. Effects of some centrally acting drugs upon learning of escape and avoidance habits. Journal of Comparative and Physiological Psychology, 1960, 53, 33-37.

Thompson, R. W., Piroch, J., Fallen, D., \& Hatton, D. A central cholinergic inhibitory system as a basis of tonic immobility (animal hypnosis) in chickens. Journal of Comparative and Physiological Psychology, 1974, 87, 507-512.

(Received for publication November 7, 1975; revision accepted December 19, 1975.) 